\title{
APLIKASI KOGNISI DALAM PENGAJARAN DAN PEMBELAJARAN KARANGAN BAHASA MALAYSIA DALAM KALANGAN PELAJAR TINGKATAN EMPAT MELALUI KAEDAH HERMENEUTIK
}

\author{
APPLICATION OF COGNITION IN THE TEACHING AND LEARNING BAHASA \\ MALAYSIA ESSAY IN FORM 4 STUDENTS BASED ON HERMENEUTICS METHOD
}

\author{
Suppiah Nachiappan, Sriraj Durailimgam, Sandra Suffian \\ Fakulti Pembangunan Manusia \\ Universiti Pendidikan Sultan Idris, Tanjong Malim, Perak \\ suppiah@fpm.upsi.edu.my
}

\begin{abstract}
ABSTRAK
Kajian ini adalah satu usaha untuk mengkaji aplikasi kognisi dalam pengajaran dan pembelajaran karangan Bahasa Malaysia dalam kalangan pelajar tingkatan 4 berdasarkan kaedah Hermeneutik. Kaedah Hermeneutik merupakan satu cara atau kaedah tersirat yang digunakan untuk menginterpretasi teks dan mencari makna di sebaliknya. Oleh itu, kajian ini adalah untuk mengetahui perkembangan kognisi dalam P\&P yang efektif untuk menulis karangan Bahasa Malaysia. Kajian ini melibatkan 10 orang pelajar dan 2 orang guru sebagai responden. Hasil daripada kajian didapati terdapat pelbagai cara yang digunakan oleh pelajar dan guru untuk meningkatkan pengetahuan dalam penulisan karangan Bahasa Malaysia. Antara cara-cara yang digunakan oleh guru dan pelajar adalah seperti menggunakan bahan rujukan, menggunakan internet, mendapatkan bantuan guru, melatih pelajar, membaca keratan akhbar, meminta bantuan guru pakar dan memberikan tugasan dengan mengingati perkara yang relevan dan berkaitan dengan tajuk untuk meningkatkan pengetahuan dalam penulisan karangan Bahasa Malaysia.
\end{abstract}

Kata kunci: kognisi, karangan Bahasa Malaysia, Kaedah Hermeneutik

\begin{abstract}
This study is an attempt to study the application of cognition in the teaching and learning of Bahasa Malaysia essay in Form 4 students based on the Hermeneutics method. Hermeneutical method is an implied way or method used to interpret texts and find meaning on the contrary. Therefore, this study is to know the development of cognition in P\&P that is effective in writing Bahasa Malaysia essays. This study involves 10 students and 2 teachers as a respondents. The results of the study found that there are various ways that students and teachers use to improve their knowledge in Bahasa Malaysia essay writing. Among the ways teachers and students use are using reference materials, using the internet, obtaining teacher assistance, training students, reading newspaper cutting, asking for expert teacher assistance and assigning tasks to remember relevant and related topics to improve knowledge in writing in Bahasa Malaysia.
\end{abstract}

Keywords: cognition, Bahasa Malaysia essay, Hermeneutical Method

\section{PENGENALAN}

Bahasa Malaysia merupakan salah satu mata pelajaran yang penting untuk diberi tumpuan oleh pelajar.

Dalam kemahiran menulis karangan terdapat dua objektif:

- Membina kebolehan mengungkapkan fikiran secara lisan dan tulisan dengan menggunakan bahasa yang betul dan kemas. 
- Membina kebolehan memperluaskan sesuatu idea atau perkara dengan cara tersusun, padat dan meyakinkan.

Objektif tersebut jelas menyatakan bahawa guru perlu memberi perhatian yang sewajar kepada kemahiran intelektual dalam proses penulisan karangan. Kegagalan pembinaan kemahiran intelektual akan menggagalkan tujuan utama sukatan pelajar Bahasa Malaysia Sijil Pelajaran Malaysia (SPM) demi menyediakan golongan pelajar yang kreatif, inovatif dan rasional melalui proses penulisan karangan Bahasa Malaysia. Pihak guru haruslah memperkukuhkan strategi mengajar ketika proses pengajaran dan pembelajaran ( $\mathrm{p} \& \mathrm{p}$ ) dalam bilik darjah untuk merealisasikan tujuan KPM.

Beberapa kajian tentang kaedah mengajar penulisan karangan Bahasa Malaysia menunjukkan bahawa terdapat perhubungan yang rapat antara kaedah mengajar dengan prestasi menulis karangan Bahasa Malaysia. Ini membuktikan bahawa bahasa merupakan wahana yang membantu dalam pelbagai jenis pengetahuan termasuklah dalam penulisan karangan.

Menurut Glatthorn (2010), penulisan karangan Bahasa Malaysia diajar mengikut naluri dan cita rasa guru tanpa berlandaskan kaedah pengajaran dan pembelajaran penulisan karangan yang sesuai dan berkesan. Oleh yang demikian, guru perlu dibimbing untuk mengajar penulisan karangan dengan betul. Para pendidik juga kurang menyedari bahawa penulisan karangan Bahasa Malaysia adalah berkaitan dengan melahirkan fikiran dan perasaan yang mempunyai tujuan, himpunan fakta, pendapat serta idea yang dipilih dan tersusun agar menggambarkan maksud dan kandungan yang boleh difahami dan dihayati oleh orang lain. Oleh itu, keberkesanan tulisan ditentukan berdasarkan sejauh mana kerelevanan dan keutuhan fakta-fakta yang dibentangkan semasa menulis sebuah karangan.

Justeru, bentuk pengajaran yang sesuai perlu diamalkan oleh guru agar kemahiran mengarang dapat diajar dengan lebih berkesan kepada pelajar di sekolah. Proses mengarang dianggap sebagai satu proses yang bergerak dalam bentuk berurutan. Di samping itu, proses mengarang merupakan satu proses dinamik yang memperlihatkan pergerakan berulangan dan bertindanan antara satu proses dengan satu proses yang lain. Maka, penyelarasan bentuk pengajaran guru dalam proses $\mathrm{p} \& \mathrm{p}$ penulisan karangan Bahasa Malaysia dalam kalangan pelajar adalah sangat penting.

Elin Lindawati (2012) telah mengkaji penulisan dan kemampuan kognisi anak. Kajian ini telah dijalankan di TK Mardiswi Yogyakarta menggunakan dua orang pelajar. Beliau menjalankan kajian kualitatif Hermeneutik. Hasilnya beliau dapati kemampuan kognisi anak memerlukan latihan dan bimbingan yang baik dalam menuliskan karangan Bahasa Malaysia yang baik. Beliau membuat kesimpulan bahawa kemampuan kognisi boleh dipertingkatkan dengan latihan dan bimbingan dalam menghasilkan sebuah karangan Bahasa Malaysia yang bermutu tinggi. Selain itu, menurut Suppiah (2013), melalui struktur kognisi dapat membincangkan idea yang menjurus kepada kategori maklumat yang dapat diterjemahkan kepada perkataan dan perbualan untuk memahami dengan jelas. Oleh itu, hal ini sekaligus mampu melatih anak-anak dalam membimbing mereka menggunakan kaedah yang betul dalam penulisan karangan Bahasa Malaysia.

Menurut Hazel Rose Markus (2010), personaliti mempengaruhi kognisi, emosi dan motivasi. Pelajar daripada jenis personaliti yang berlainan mempunyai kemampuan kognisi yang beza. Sebagai contohnya, pelajar yang mempunyai personaliti ekstrovert mempunyai kemampuan kognisi yang lebih tajam berbanding pelajar yang mempunyai personaliti introvert. Oleh yang demikian, kognisi juga mempengaruhi pembentukan personaliti individu. Pelajar yang mempunyai personaliti ekstrovert mampu untuk mengetengahkan idea-idea yang bernas dan baik.

Hall dan William (2010) telah menjalankan kajian ke atas pelajar-pelajar lelaki dan perempuan di sebuah sekolah dan didapati guru dan ibu bapa mempengaruhi tahap kognisi mereka dan penghasilan karangan yang baik. Hasil kajian didapati bahawa terdapat perbezaan di antara pelajar lelaki dan pelajar perempuan dari segi pengaruh ibu bapa terhadap tahap kognisi mereka. Hal ini menunjukkan bahawa pelajar-pelajar perempuan mempunyai aspirasi tahap kognisi yang bertaraf tinggi.

Menurut Abdul Razak dan Sarimah (2010), motivasi intrinsik pelajar Sekolah Menengah Teknik dalam melakukan tugasan di makmal hanya berada pada tahap sederhana. Hanya dua gaya pembelajaran yang paling digunakan, iaitu penyesuaian dan pemusatan. Pelajar yang mengikuti gaya 
pembelajaran ini mempunyai tahap kebolehan kognitif yang tinggi. Pelajar yang mempunyai gaya kognisi yang tinggi dapat mengaplikasikan maklumat yang lebih berguna dalam penulisan karangan.

Hal ini disokong oleh Suppiah (2014), iaitu menggunakan struktur bahasa dalam kemahiran berbahasa mampu memperkayakan kognisi mengenai idea yang disampaikan. Perkembangan idea dibantu oleh pemikiran penulis kerana proses pemikiran dan kognisi dapat mempengaruhi bahasa dan perkembangan psikologi.

Ruhizan Mohd Yassin, Mohd Jasmy Abd Rahman, Norlena Salamuddin dan Rosadah Abd Majid (2010) telah menjalankan kajian proses kognisi dalam kalangan pelajar cemerlang dan tidak cemerlang. Hasil ini adalah untuk mengenal pasti proses kognitif dan strategi pembelajaran yang digunakan oleh 118 orang pelajar tahun 2 UKM, Bangi. Pelajar-pelajar terdiri daripada pelajar yang cemerlang dan tidak cemerlang berdasarkan purata gred kumulatif mereka. Kaedah penyelidikan yang digunakan adalah kaedah 'ex post facto atau causal comparative'. Data dianalisis dengan menggunakan analisis faktor dan statistik inferensi. Hasil daripada analisis faktor, empat faktor utama (strategi) dikenal pasti, iaitu motivasi pencapaian, pembelajaran operasional, hafalan dan pendekatan global. Kajian juga mendapati wujud korelasi negatif antara pencapaian pelajar dengan pembelajaran operasional dan hafalan. Pelajar-pelajar pencapaian rendah lebih cenderung kepada orientasi pencapaian, penghasilan semula, pembinaan makna, pembelajaran pemahaman dan pembelajaran operasional berbanding pelajar-pelajar pencapaian tinggi. Kesimpulan yang dapat dibuat daripada kajian ini adalah terdapat beberapa perbezaan antara tahap dalam proses kognitif pelajar-pelajar cemerlang dan tidak cemerlang.

Othman (2010) telah menjalankan kajian terhadap pelajar-pelajar tingkatan tiga di sepuluh buah sekolah di daerah Johor Bharu. Kajiannya berkaitan dengan kesan proses kognisi terhadap tingkah laku murid. Analisis kajian menunjukkan kecerdasan murid-murid mempunyai kesan terhadap tingkah laku akademik. Perkembangan kognitif yang baik amat diperlukan untuk peningkatan pencapaian pelajar dalam pendidikan.

Maimunah (2012) telah menjalankan kajian untuk melihat bagaimana corak layanan ibu bapa dan hubungannya terhadap konsep kognisi remaja yang bertingkah laku delinkuen. Hasil kajian mendapati tidak terdapat hubungan yang signifikan di antara corak layanan ibu bapa dengan konsep kognisi remaja yang bertingkah laku delinkuen. Oleh yang demikian, perkembangan kognitif adalah tidak bergantung semata-mata terhadap layanan ibu bapa. Maka, setiap pelajar berkebolehan dengan diri sendiri untuk meningkatkan tahap kognitif.

Danishwaran (2011) menjalankan kajian berkaitan cara-cara belajar menulis karangan Bahasa Malaysia SPM dalam kalangan pelajar cemerlang berdasarkan analisis Hermeneutik. Kajian ini melibatkan 10 orang responden yang mendapat keputusan cemerlang dalam subjek Bahasa Malaysia SPM semasa menduduki peperiksaan SPM tahun 2010. Hasil daripada kajian ini didapati terdapat pelbagai cara belajar yang digunakan oleh 3 kategori pelajar cemerlang yang mendapat gred $\mathrm{A}+, \mathrm{A}$ dan A-. Antara cara-cara belajar yang digunakan oleh ketiga-tiga kategori pelajar cemerlang adalah seperti menulis simpulan bahasa, peribahasa dan kosa kata dalam nota kecil supaya dapat mengulang kaji, membuat banyak latihan mengarang dan menyuruh guru mata pelajaran Bahasa Malaysia menyemak latihan tersebut supaya pelajar dapat mengetahui kesilapan.

\section{PERNYATAAN MASALAH}

Demi menguasai kemahiran menulis karangan Bahasa Malaysia, perhatian yang kritis wajib diberikan oleh semua pihak agar aspek kognisi dapat diaplikasikan oleh pelajar semasa menulis karangan. Hal ini kerana, pada masa ini, warga manusia bukan sahaja menulis karangan untuk tujuan akademik tetapi mereka menggunakan perkara ini dalam permohonan kerja dan juga melanjutkan pelajaran. Keadaan ini jelas mengatakan aspek kognisi merupakan elemen penting untuk dipraktikkan dalam penulisan karangan Bahasa Malaysia untuk menghasilkan karangan yang mempunyai tahap intelektual yang tinggi.

Pelaksanaan pengajaran yang dijalankan oleh guru tidak selaras dengan sifat proses mengarang pelajar. Pengajaran dan pembelajaran lebih banyak bersifat sehala dan kurang memberi tumpuan pada aktiviti berbahasa pada tahap kognisi tertinggi. Perkara sebegini sudah tentunya tidak 
dapat menggalakkan pertumbuhan kognisi pada aras yang lebih tinggi dalam kalangan pelajar semasa menulis karangan Bahasa Malaysia. Namun begitu, menurut Suppiah (2013), proses kognisi dan afeksi membantu pelajar menjana ilmu pengetahuan dan pengalaman untuk dimuatkan dalam penulisan karangan mereka sewaktu menjawab soalan peperiksaan di sekolah. Kesimpulannya, proses pemikiran dalam penulisan karangan adalah suatu tugas yang dilakukan secara abstrak.

Melalui kefahaman umum dan pengalaman tanpa teknik yang sesuai, para pendidik lebih gemar menggunakan pengalaman sendiri untuk mengajar kemahiran penulisan karangan Bahasa Malaysia. Lantaran itu, menyebabkan ramai pelajar yang masih lemah dalam menghasilkan penulisan karangan Bahasa Malaysia yang baik dan cemerlang. Oleh itu, perlu mengkaji dan mencari penyelesaian untuk mengatasi masalah ini. Aplikasi kognisi adalah penting untuk menghasilkan karangan pada tahap intelektual yang tinggi.

\section{OBJEKTIF KAJIAN}

- Mengenal pasti cara-cara meningkatkan pencapaian karangan Bahasa Malaysia dalam Kalangan pelajar tingkatan 4 .

- Mengenal pasti masalah yang cikgu hadapi dalam pengajaran dan pembelajaran (P\&P) karangan Bahasa Malaysia kalangan pelajar tingkatan 4.

- Mengenal pasti cara-cara cikgu mengatasi masalah pengajaran dan pembelajaran (p\&p) karangan Bahasa Malaysia dalam kalangan pelajar tingkatan 4.

\section{SOALAN KAJIAN}

- Bagaimanakah cara-cara meningkatkan pencapaian karangan Bahasa Malaysia dalam Kalangan pelajar tingkatan 4 ?

- Apakah masalah yang cikgu hadapi dalam pengajaran dan pembelajaran (P\&P) karangan Bahasa Malaysia dalam kalangan pelajar tingkatan 4 ?

- Huraikan cara-cara cikgu mengatasi masalah pengajaran dan pembelajaran (p\&p) karangan Bahasa Malaysia dalam kalangan pelajar tingkatan 4 ?

\section{BATASAN KAJIAN}

Kajian ini dijalankan di salah sebuah sekolah menengah di Ayer Tawar Perak. Seramai 10 orang pelajar tingkatan dan 2 orang guru yang terlibat dalam kajian ini. Berikutan itu, dapatan dari kajian ini tidak boleh mewakili populasi pelajar seluruh negara yang terdiri daripada latar belakang yang berbeza. Oleh itu, keputusan kajian ini tidak boleh mewakili populasi keseluruhan pelajar dan guru walaupun sampel kajian terdiri dari pelbagai etnik dan golongan.

\section{KAEDAH KAJIAN}

Menurut Loganathan (1996) dan Suppiah (2016), kaedah Hermeneutik dapat menghalusi makna teks sebagai cara untuk menyampaikan pengalaman, kepercayaan dan penghakiman daripada seseorang atau komuniti ke atas orang lain. Oleh hal demikian, kaedah ini mampu menginterpretasi karya berdasarkan andaian dan pembayang yang terdapat dalam konteks penulisan.

Kajian ini merupakan kajian yang berbentuk deskriptif yang menggunakan analisis Hermeneutik. Analisis Hermeneutik melihat setiap individu itu unik. Kajian ini berkait rapat dengan psikologi tingkah laku manusia. Maka kaedah kualitatif amat bersesuaian. Hermeneutik didefinisikan sebagai proses menginterpretasikan teks.

Menurut Danishwaran (2011), kaedah ini mengutamakan penginterpretasian teks dalam konteks sosiobudaya dan sejarah dengan mendedahkan makna yang tersirat dalam sesebuah teks yang diselidik. Hermeneutik juga berfokus kepada teks sebagai sumber data. Kaedah yang digunakan dalam pendekatan Hermeneutik bermula dengan teks. Kemudian, dikenal pasti informasi yang bermakna dalam teks yang kemudiannya digunakan pula untuk menjana kategori daripada sekumpulan teks. 


\section{Unsur-unsur Instrumen, Validiti dan Kebolehpercayaan}

Elemen-elemen yang biasanya terdiri daripada satu set soal selidik validiti dan kebolehpercayaan adalah sangat tinggi dalam kaedah sains Hermeneutik. Kebolehpercayaan dan validiti instrumen itu dibuktikan dengan menggunakan data-data tertentu. Namun begitu, dalam kajian ini tiada instrumen yang melibatkan sebarang data. Sebaliknya, di dalam kaedah Hermeneutik dibincangkan tentang tiga elemen utama, iaitu yang pertamanya adalah berkaitan dengan kebolehpercayaan, teks kajian dan yang seterusnya adalah berkaitan dengan kesahihan metateks dan juga kecekapan dalam proses pengaliran kefahaman dari struktur luaran kepada struktur dalaman.

\section{Metateks}

Tinjauan dalam kajian ini melibatkan interpretasi yang dibuat terhadap karangan pelajar yang mengandungi penjelasan terhadap makna yang dicari dalam teks karangan. Aspek yang cuba difahami dalam karangan yang dianalisis ialah kewujudan unsur-unsur motivasi yang mendorong murid menghasilkan karangan yang baik. Hal ini disokong oleh Suppiah (2016), metateks merupakan kaedah mendapatkan hasil interpretasi karangan dari teks yang melibatkan unsur struktur luaran, iaitu makna tersirat dan dalaman, iaitu makna tersurat dari teks untuk mencapai makna yang ingin disampaikan.

Di samping itu, melalui kaedah Hermeneutik teks yang ditulis oleh responden dalam kajian akan dianalisis secara interpretif. Selain itu, penulisan jawapan dalam bentuk teks yang dijawab oleh pelajar dan guru telah diproses dan dianalisis untuk melihat elemen aplikasi kognitif dalam pengajaran dan pembelajaran karangan Bahasa Malaysia dalam kalangan pelajar tingkatan 4. Rajah 1 menerangkan proses tersebut.

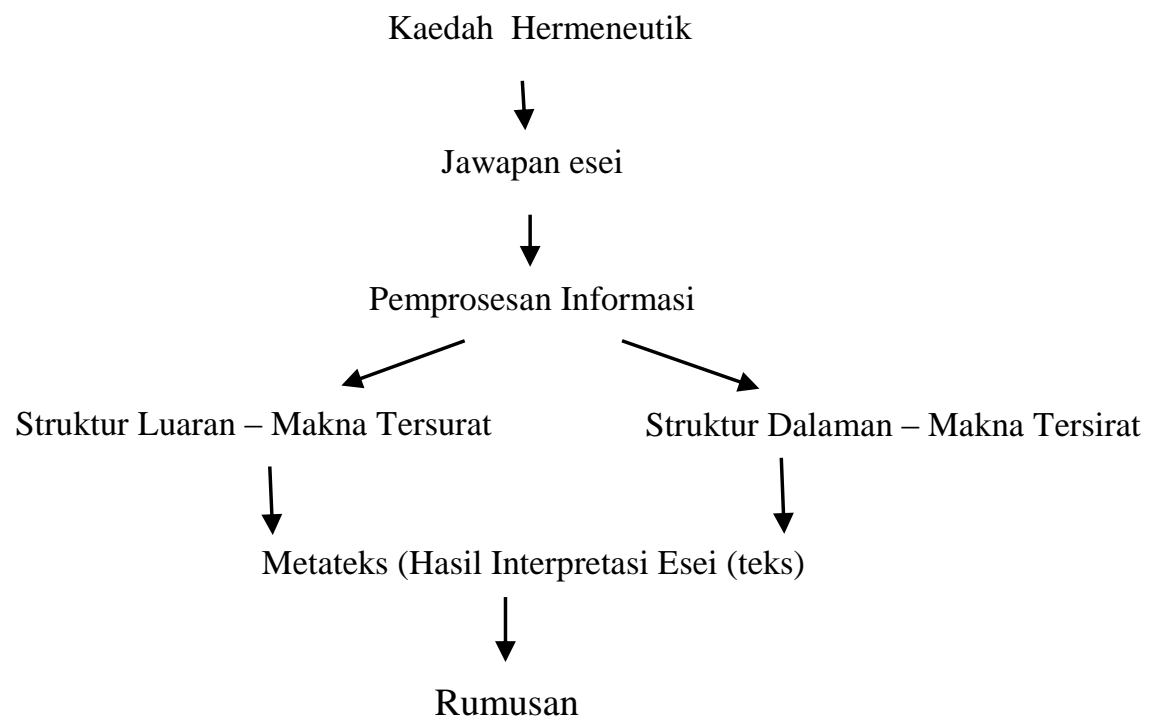

Rajah 1: Tatacara Analisis Karangan Menggunakan Kaedah Hermeneutik

\section{PENGANALISISAN DATA}

Data yang diperoleh dianalisis dengan menggunakan interpretasi teks. Para responden dikehendaki untuk menjawab kepada soalan yang dikemukakan. Setelah itu, jawapan yang mereka tulis dianalisis dengan menggunakan kaedah Hermeneutik. 


\section{PERBINCANGAN DAPATAN KAJIAN}

Perbincangan dapatan kajian telah dibuat berpandukan borang soal selidik yang telah dijawab oleh pelajar seramai 10 orang. Mereka telah menjawab sebanyak satu soalan berbentuk pendapat dalam borang yang telah diedarkan. Berikut adalah soalan kajian 1 yang telah dijawab oleh pelajar.

Soalan Kajian 1: Bagaimanakah cara-cara meningkatkan pencapaian karangan Bahasa Malaysia dalam Kalangan pelajar tingkatan 4?

Jadual 1: Senarai aktiviti peningkatan pencapaian karangan Bahasa Malaysia dalam kalangan pelajar tingkatan 4

\section{Aktiviti Peningkatan Pencapaian Dalam \\ Karangan Bahasa Melayu}

Bahan Rujukan

Internet

Bantuan Guru

Tumpuan dalam bilik darjah

Perpustakaan

Belajar Secara Kumpulan

Tuisyen

Facebook

Inisiatif sendiri

Perkataan Darjat tinggi

Latih tubi

Seminar / bengkel

Artikel/ Risalah

Berkomunikasi dalam Bahasa Malaysia di rumah

Menghafal Karangan

Rancangan forum Bahasa Malaysia

Peta Minda

\section{Kekerapan Aktiviti Pelajar}

R4, R5, R6, R8, R9, R10

R1, R2, R7, R8

R1, R2, R7, R8

R5, R6, R8

R2, R7, R9

R2, R7, R9

$\mathrm{R} 1, \mathrm{R} 9$

$\mathrm{R} 2, \mathrm{R} 10$

$\mathrm{R} 3, \mathrm{R} 4$

R3,R4

R6,R10

R10

R3

R4

R5

R8

R1

Jadual 1 menunjukkan senarai aktiviti yang dilakukan untuk meningkatkan pencapaian dalam karangan Bahasa Malaysia. Antara tumpuan aktiviti tersebut ialah penggunaan bahan rujukan, internet, bantuan guru, tumpuan dalam bilik darjah, perpustakaan dan belajar secara berkumpulan.

\section{Soalan Kajian Bahagian Guru}

Perbincangan dapatan kajian untuk guru dibuat berdasarkan kepada borang soal selidik yang dijawab oleh 2 orang guru yang mengajar mata pelajaran Bahasa Malaysia. Mereka menjawab sebanyak dua soalan berbentuk pendapat dalam borang soal selidik yang diedarkan kepada mereka. Berikut adalah soalan kajian 1 dan soalan kajian 2 yang dijawab oleh guru.

Soalan Kajian 2: Apakah masalah yang cikgu hadapi dalam pengajaran dan pembelajaran (P\&P) karangan Bahasa Malaysia kalangan pelajar tingkatan 4? 
Jadual 2: Senarai masalah yang dihadapi oleh guru dalam pengajaran dan pembelajaran karangan Bahasa Malaysia dalam kalangan pelajar tingkatan 4

\begin{tabular}{|c|}
\hline $\begin{array}{l}\text { Masalah yang Dihadapi Oleh Guru Dalam P\&P } \\
\text { Karangan Bahasa Malaysia }\end{array}$ \\
\hline
\end{tabular}

Pelajar yang kurang berpengetahuan

Penterjemahan bahasa lain terus kepada Bahasa Malaysia

Pelajar yang menggunakan gaya bahasa ibunda semasa

penulisan karangan Bahasa Malaysia

Kunci tajuk soalan

Mengenal pasti isi karangan

Keliru dengan pelajar yang menggabungkan isi

Kesalahan ejaan yang banyak
GURU A

GURU A

GURU A

GURU B

GURU B

GURU B

GURU B

Berdasarkan Jadual 2 didapati guru A menghadapi pelbagai cabaran dalam pengajaran dan pembelajaran karangan Bahasa Malaysia dalam kalangan pelajar tingkatan 4. Antaranya ialah pelajar yang kurang berpengetahuan. Pelajar ini akan mengalami kesukaran dalam mencari isi-isi utama. Hal ini disebabkan oleh pelajar yang kurang membaca bahan-bahan ilmu.

Pada masa yang sama, mengikut guru A pelajar yang mempelajari dwibahasa mengalami kesukaran penulisan karangan Bahasa Malaysia disebabkan penterjemahan bahasa lain secara langsung kepada Bahasa Malaysia yang mempunyai banyak kesilapan dalam Bahasa Inggeris. Menurut guru A, pelajar juga menggunakan gaya bahasa ibunda semasa penulisan karangan dan hal ini menyukarkan guru sewaktu mengajar karangan Bahasa Malaysia.

Berdasarkan Jadual 2, menurut guru B terdapat empat perkara yang menjadi masalah ketika mengajar karangan Bahasa Malaysia. Pertamanya, guru menghadapi masalah dengan pelajar yang keliru dan tidak mengetahui kunci tajuk soalan yang hendak ditulis dengan tepat. Sebagai contohnya, terdapat pelajar yang tidak mahir untuk mengenal pasti kata kunci kepada soalan. Hal ini menyebabkan guru menghadapi masalah yang besar untuk mengajar perkara yang asas terlebih dahulu yang mana perkara tersebut dapat diketahui dengan mudah tanpa bimbingan guru.

Selain itu, guru juga menghadapi masalah untuk mengenal pasti isi karangan disebabkan oleh pelajar yang tidak merangka ayat secara tersusun. Perkara ini adalah umum dan guru terpaksa mencari isi karangan dalam satu perenggan semata-mata untuk memastikan pelajar mendapat markah lulus. Guru juga keliru dengan pelajar yang menggabungkan isi dalam satu perenggan yang panjang. Hal ini menyebabkan guru menghadapi masalah untuk menyemak karangan yang mengandungi banyak kesalahan ejaan.

Soalan Kajian 3: Huraikan cara-cara cikgu mengatasi masalah pengajaran dan pembelajaran (p\&p) karangan Bahasa Malaysia dalam kalangan pelajar tingkatan 4?

Jadual 3: Senarai Cara-Cara Guru Mengatasi Masalah Pengajaran dan Pembelajaran Karangan Bahasa Malaysia Dalam Kalangan Pelajar Tingkatan 4

\begin{tabular}{ll}
\hline Senarai Cara-Cara Guru Mengatasi Masalah & Kek \\
\hline $\begin{array}{l}\text { Memberikan tugasan dengan mengingati perkara yang } \\
\text { relevan dan berkaitan dengan tajuk. }\end{array}$ & GURU A \\
Meminta bantuan guru pakar & GURU A \\
Mengemaskinikan pengetahuan & GURU B \\
Menyediakan fail berdasarkan sesuatu tajuk & GURU B \\
Keretan akhbar untuk pelajar yang lemah & GURU B \\
Melatih pelajar & GURU B
\end{tabular}


Berdasarkan Jadual 3 didapati responden A menggunakan dua langkah bagi mengatasi masalah pengajaran dan pembelajaran karangan Bahasa Malaysia. Pertamanya adalah dengan menggunakan teori kontruktivisme yang mana guru seharusnya memberikan tugasan yang dapat membantu pelajar menulis karangan dengan mengingati perkara-perkara relevan yang berkaitan dengan tajuk. Menurut guru A, guru juga boleh meminta bantuan guru pakar sebagai pemudah cara dalam proses pengajaran dan pembelajaran untuk membantu mengaplikasikan pengetahuan dalam karangan Bahasa Malaysia. Guru pakar mempunyai pengalaman yang luas dan lebih mendalam dalam Bahasa Malaysia.

Guru B pula menyatakan bahawa setiap guru yang mengajar karangan Bahasa Malaysia hendaklah mengemaskinikan pengetahuan dengan isu-isu semasa. Perkara ini penting semasa mengajar karangan Bahasa Malaysia. Selain itu, guru juga haruslah menyediakan fail berdasarkan sesuatu tajuk. Perkara sebegini boleh membantu guru untuk mengajar dengan mudah kerana maklumat yang diperlukan mudah diakses pada bila-bila masa.

Di samping itu, guru juga perlu menyediakan keratan akhbar untuk pelajar yang lemah sebagai rujukan tambahan. Selain itu, guru juga harus melatih pelajar untuk membaca, memahami dan menghafal isi-isi penting dalam bilik darjah. Akhir sekali, guru juga perlu menjadi sebagai fasilitator ketika mengajar karangan Bahasa Malaysia. Dengan bimbingan dan tunjuk ajar yang betul guru boleh melatih pelajar untuk menulis karangan Bahasa Malaysia.

\section{APLIKASI KOGNISI DALAM PENGAJARAN DAN PEMBELAJARAN KARANGAN BAHASA MALAYSIA MELALUI KAEDAH HERMENEUTIK}

\section{Perbincangan Dapatan Kajian Daripada Soal Selidik Pelajar}

Daripada 17 aktiviti yang telah diutarakan oleh pelajar, terdapat kaedah pembelajaran yang menggunakan bahan rujukan, internet dan bantuan daripada guru adalah aktiviti yang tertinggi dalam meningkatkan prestasi penulisan karangan Bahasa Malaysia dalam kalangan pelajar tingkatan 4.

Pertamanya, bahan rujukan yang boleh didapati dengan mudah oleh pelajar. Pada zaman kini, terdapat pelbagai buku rujukan daripada pelbagai jenama yang boleh dibeli oleh pelajar dengan harga yang berpatutan. Kemudahan internet merupakan salah satu sumber maklumat yang paling berkuasa dan penting pada zaman ini. Hubungan antara teknologi dengan remaja begitu erat dan tidak dapat dipisahkan. Pelajar tingkatan 4 di sekolah kajian lebih gemar menggunakan kemudahan internet dalam meningkatkan prestasi penulisan karangan Bahasa Malaysia berbanding dengan kaedah pembelajaran secara tradisional. Hal ini mungkin disebabkan kemudahan jalur lebar yang terdapat di sekolah kajian ini. Maka, pelajar lebih mudah untuk mengakses maklumat dengan menggunakan kemudahan makmal komputer dan dapat mewujudkan suasana pembelajaran yang menarik kepada pelajar.

Selain itu, perbelanjaan penggunaan internet adalah murah, malah penggunaan internet juga menggalakkan penglibatan pelajar. Situasi ini sudah tentunya menggalakkan peningkatan aspek kognisi dalam kalangan pelajar. Jika meninjau bantuan daripada guru yang mencatatkan aktiviti yang kedua terbanyak digunakan oleh pelajar dalam meningkatkan prestasi penulisan karangan Bahasa Malaysia. Guru adalah mesra dan mudah didekati di sekolah kajian . Selain itu, guru ini juga membuat kelas tambahan semasa cuti sekolah. Oleh itu, pelajar mudah mendapatkan maklumat daripada guru.

Kesimpulannya, hubungan yang rapat dan mesra membolehkan pelajar di sekolah kajian yang memilih bantuan guru untuk meningkatkan prestasi penulisan karangan Bahasa Malaysia. Malah, tidak dapat dinafikan bahawa maklumat yang diperoleh daripada guru adalah tepat dan benar. Oleh yang demikian, pelajar memilih untuk mendapatkan maklumat dan bimbingan sebagai tunjuk ajar daripada guru untuk meningkatkan prestasi penulisan karangan Bahasa Malaysia. Walau bagaimanapun, terdapat juga aktiviti-aktiviti lain yang turut digunakan oleh pelajar. Apa yang dipentingkan oleh pengkaji adalah aspek kognisi dapat dipraktikkan dengan banyak melalui bahan rujukan, internet dan bantuan daripada guru disebabkan penglibatan pelajar adalah sangat aktif. Tetapi, pada masa yang sama, peranan aktiviti-aktiviti lain dalam mempertingkatkan prestasi penulisan karangan Bahasa Malaysia tidak dapat dinafikan. Malah, kesemua aktiviti yang digunakan 
oleh pelajar dapat mempertingkatkan prestasi penulisan karangan Bahasa Malaysia dan seterusnya menggalakkan peningkatan aspek kognisi dalam kalangan pelajar.

\section{Perbincangan Dapatan Kajian Daripada Soal Selidik Guru}

Setelah ditinjau dan dilihat dapatan kajian yang mengandungi 2 soalan, didapati pelbagai langkah yang perlu dilakukan oleh kedua-dua pihak sama ada dari kalangan pelajar mahupun dari kalangan guru. Tetapi, setelah melihat dengan lebih mendalam, didapati guru perlu memainkan peranan yang sewajarnya dalam memastikan pengajaran dan pembelajaran karangan Bahasa Malaysia dalam kalangan pelajar tingkatan 4 menjadi lebih menarik.

Guru perlu menjalani bengkel penulisan karangan untuk mengenal pasti bentuk perlakuan dan proses mengarang yang dialami semasa menulis karangan di bilik darjah. Melalui bengkel penulisan ini, para guru dapat menyedari apa yang berlaku apabila pelajar menulis karangan. Selain itu, pengetahuan dan kesedaran guru terhadap sifat proses mengarang membolehkan mereka lebih berupaya untuk merancang kegiatan dan melibatkan diri mereka bagi mempertingkatkan mutu kemahiran menulis karangan dalam kalangan pelajar. Sebagai contohnya, dalam situasi pengajaran dan pembelajaran di dalam kelas, guru bukan sahaja pembimbing dan pemudah cara bagi mewujudkan persekitaran kelas mengarang yang kondusif.

Pengkaji juga mendapati bahawa guru juga perlu berperanan sebagai pemudah cara. Guru perlu memudahkan proses penulisan karangan yang dilalui pelajar di dalam kelas dengan memberi bantuan yang diperlukan semasa menulis. Dengan itu, program penulisan karangan yang dilalui pelajar di dalam kelas dengan memberi bantuan yang diperlukan semasa menulis. Maka, program pendidikan guru khususnya dalam penyediaan bakal guru perlu mengambil kira ketiga-tiga peranan tersebut dalam proses pengajaran dan pembelajaran kemahiran mengarang. Oleh yang demikian, guru mempunyai peranan penting dalam memastikan para pelajar mendapat proses pengajaran dan pembelajaran yang baik agar mereka dapat menulis karangan dengan baik dengan meningkatkan aspek kognisi semasa menulis karangan Bahasa Malaysia.

\section{PERBINCANGAN APLIKASI KOGNISI DALAM PENULISAN KARANGAN BAHASA MELAYU}

Menurut Mohd Makhzan Musa (2012), Bahasa Melayu merupakan subjek yang paling penting di negara kita. Oleh itu, pelajar diwajibkan untuk lulus dalam peperiksaan SPM. Pada masa yang sama, Bahasa Melayu juga merupakan bahasa rasmi dan digunakan secara meluas dalam kalangan rakyat di Malaysia secara umum. Sebagai warga Malaysia, menguasai Bahasa Malaysia dikatakan sebagai suatu kewajipan.

Menurut Md Nordin Yusof (2011), guru perlu memainkan peranan yang penting dalam meningkatkan kemahiran penulisan karangan Bahasa Melayu. Misalnya, guru harus mempelbagaikan kaedah dalam proses pengajaran dan pembelajaran agar pelajar tidak mudah bosan. Kaedah pembelajaran secara permainan role play bukan sahaja meningkatkan minat pelajar, malah dapat meningkatkan motivasi pelajar untuk belajar mengarang penulisan karangan Bahasa Melayu.

Selain itu, guru yang menyampaikan ilmu pengetahuan dianggap menumpukan perhatian terhadap perkembangan kognisi pelajar. Malah, penyampaian ilmu pengetahuan berdasarkan subjek amat bergantung pada kategori dan penerapan domain kognisi yang disarankan oleh Benjamin Bloom. Jika melihat usaha-usaha yang dilakukan oleh guru di sekolah kajian jelas menunjukkan bahawa mereka telah mencuba pelbagai kaedah dalam usaha untuk memastikan unsur kognisi dalam kalangan pelajar tingkatan 4 dapat dipertingkatkan dengan baik.

Kajian ini jelas menunjukkan keberkesanan pengajaran dan pembelajaran bergantung pada cara guru mengajar dengan menghubungkan domain kognisi dalam pengajaran dan pembelajaran. Proses pengajaran dan pembelajaran yang berjaya amat bergantung pada guru. Dalam menjayakan perkara tersebut, guru harus menyediakan rancangan pengajaran berpandukan domain kognisi untuk memanfaatkan ilmu secara maksimum. Pelajar juga harus mengoptimumkan penyampaian dan penguasaan ilmu pengetahuan dalam subjek penulisan karangan Bahasa Melayu oleh guru yang 
mengajar. Selain itu, konsep kognisi perlu dihubungkan dalam pembelajaran efektif melalui proses pengajaran dan pembelajaran guru.

\section{CADANGAN UNTUK PENGAPLIKASIAN KOGNISI DALAM PENULISAN KARANGAN BAHASA MELAYU}

Hasil daripada kajian ini terbuktilah bahawa terdapat beberapa langkah penting yang harus diambil oleh semua pihak untuk memastikan semua masalah yang timbul dapat diatasi. Tahap perkembangan keupayaan kognisi bergantung pada motivasi intrinsik dan ekstrinsik pelajar. Oleh itu, keupayaan kognisi harus diperkayakan melalui pelbagai teknik pengajaran. Penerokaan dan penimbaan ilmu pengetahuan juga bergantung pada proses mental yang aktif. Sekiranya, guru memahami dan mengaplikasikan proses kognisi dalam $\mathrm{P} \& \mathrm{P}$, pelajar dapat menumpukan perhatian sepenuhnya terhadap pengajaran.

Di samping itu, kesediaan guru yang penuh motivasi dan mahir dalam subjek yang diajar merupakan faktor penting yang harus dimilikinya. Penggunaan bahan bantu mengajar juga penting disebabkan guru mungkin akan berhadapan dengan pelajar dari segi tahap keupayaan mental, iaitu yang cemerlang, sederhana dan lemah dari segi kognisi. Maka, cabaran kepada guru adalah mengajar pelajar sehingga mereka menguasai ilmu pengetahuan subjek yang diajar dengan maksimum. Dalam pada itu, cabaran guru termasuklah membentuk pelajar bertingkah laku baik dan daripada masalah disiplin.

\section{RUJUKAN}

Abdul Razak dan Sarimah. (2010). Hubungan di antara minat kerjaya \& personaliti dari segi bangsa dan jantina, berdasarkan Teori Holland. (Latihan Ilmiah yang tidak diterbitkan). Bangi: Universiti Kebangsaan Malaysia.

Danishwaran. (2011). Cara-Cara belajar menulis karangan Bahasa Melayu SPM dalam kalangan pelajar cemerlang. (Kertas projek yang tidak diterbitkan). Tanjong Malim: Universiti Pendidikan Sultan Idris.

Elin Lindawati. (2012). Strategi Memori Dan Kognitif. Yogyakarta: Indonesia.

Glatthorn, F. N. (2010). Foundation of Behavioral Research. New York: Holt, Rinehart and Winston Ltd.

Hall, L \& William, J. (2010). The Dynamics of Composing: Making Plans and Juggling Constraints. Dlm. L. Gregg \& Steiberg (Edi), Cognitive Process in Writing. Hillsdale, NJ: Lawrence Erbaum Assoc. 31-50.

Hazel Rose Markus. (2010). Culture and Self: Implication for Cognition, Emotion and Motivation. University Of Michigan: USA.

Maimunah. (2012). Psikologi Sosial. Siri Pengajian \& Pendidikan Utusan. Kuala Lumpur: Utusan Publications \& Distributors Sdn. Bhd.

Md Nordin Yusof. (2011). Psikologi Pendidikan 1: Psikologi Perkembangan. Kuala Lumpur: Penerbit Kumpulan Budiman.

Mohd Makhzan Musa. (2012). Pekerjaan dan Perusahaan Menurut Islam. Kuala Lumpur: Penerbit Utusan Publications.

Othman Md. Johan. (2010). Kesan konsep kendiri terhadap tingkah laku murid-murid. (Tesis PhD yang tidak diterbitkan). Bangi: Universiti Kebangsaan Malaysia.

Ruhizan Mohd Yassin, Mohd Jasmy Abd Rahman, Norlena Salamuddin dan Rosadah Abd Majid. (2010). Kesan Pendekatan Penyebatian Kemahiran Berfikir Kreatif dalam Pengajaran Karangan Berfikir Kreatif dalam Pengajaran Karangan Deskriptif dan Karangan Imaginatif dalam Kalangan Pelajar Tingakatan 4. Bangi: Universiti Kebangsaan Malaysia.

Suppiah Nachiappan. (2013). Proses Kognisi dan Afeksi: Kaedah Pedagogi Hermeneutik dan Interpretasi. Tanjong Malim: Penerbit Universiti Pendidikan Sultan Idri.s

Suppiah Nachiappan. (2015). Gaya Bahasa dan Proses Kognisi: Kaedah Pedagogi Hermeneutik dan Interpretasi. Tanjong Malim: Penerbit Universiti Pendidikan Sultan Idris.

Suppiah Nachiappan. (2016). Kaedah Hermeneutik: Kaedah Interpretasi Teks Secara Kualitatif. Tanjong Malim: Penerbit Universiti Pendidikan Sultan Idris. 